УДК 504.453:504.062.4(470.341)

ЭКОЛОГИЧЕСКИЙ АНАЛИЗ РЕГИОНАЛЬНЫХ АСПЕКТОВ

РЕАЛИЗАЦИИ ПРИОРИТЕТНОГО ПРОЕКТА «ОЗДОРОВЛЕНИЕ ВОЛГИ» В НИЖЕГОРОДСКОЙ ОБЛАСТИ

\author{
Хоботилова Е.И., Копосова Н.Н.
}

ФГБОУ ВО «Нижегородский государственный педагогический университет имени Козьмь Минина», Нижний Новгород, e-mail: coposowa.nataliya@yandex.ru

В работе изучены основные причины, негативно влияющие на экологическое состояние Волги (сброс неочищенных сточных вод и влияние плотин), проанализированы мероприятия проекта «Сохранение и предотвращение загрязнения реки Волги на территории Нижегородской области», а также рассмотрены возможные риски и проблемные моменты, которые могут возникнуть при реализации проекта. Для сохранения и улучшения экологически благоприятной обстановки на реке Волге предполагается снижение антропогенной нагрузки от сброса сточных вод ненормативного качества. В соответствии с проектом паспорта проекта данный показатель по Нижегородской области планируется снизить с 0,35 км³/год до 0,12 км³ $^{3} /$ год. На данный момент в региональный паспорт вошли 88 проектов на строительство, модернизацию и реконструкцию очистных сооружений - объектов жилищно-коммунального хозяйства на территории более чем 30 муниципальных образований. Однако ввиду отсутствия разработанного механизма государственной поддержки реализации инвестиционных проектов, правил предоставления финансовой поддержки за счет средств федерального бюджета и многих других проблемных моментов возможна задержка в реализации мероприятий по оздоровлению реки Волги. Дополнительно предлагается произвести ликвидацию (рекультивацию) объекта прошлого экологического вреда - территории Бурнаковской низины г. Нижнего Новгорода, являющейся источником диффузного загрязнения реки Волги, загрязненной в результате прошлой хозяйственной деятельности по хранению, переработке нефтепродуктов и нефтешлама. С данной территории регулярно наблюдается вынос в реку Волгу нефтепродуктов. Решение данного вопроса в план мероприятий приоритетного проекта «Сохранение и предотвращение загрязнения реки Волги на территории Нижегородской области» не вошло. Также в настоящее время не определен источник финансирования проведения мероприятия по ликвидации объекта накопленного вреда на территории Бурнаковской низины.

Ключевые слова: река Волга, экологическое состояние воды, оздоровление Волги, очистные сооружения, целевые показатели, финансирование мероприятий

\title{
ECOLOGICAL ANALYSIS OF IMPLEMENTATION REGIONAL ASPECTS OF THE PRIORITY PROJECT «HEALTH OF THE VOLGA» IN NIZHNY NOVGOROD REGION
}

\author{
Khobotilova E.I., Koposova N.N. \\ Minin Nizhny Novgorod State Pedagogical University, Nizhny Novgorod, \\ e-mail: coposowa.nataliya@yandex.ru
}

\begin{abstract}
The main factors that negatively affect the ecological state of the Volga are studied: the discharge of untreated wastewater and the influence of dams, the measures of the project «Preservation and Prevention of Pollution of the Volga River in the Nizhny Novgorod Region» are analyzed, and the possible risks and problem points that may arise when project implementation. To preserve and improve the environmentally favorable situation on the Volga River, it is planned to reduce the anthropogenic load on them from the discharge of waste water of substandard quality. In accordance with the draft project passport, this indicator for the Nizhny Novgorod Region is planned to be reduced from $0,35 \mathrm{~km}^{3} /$ year to $0.12 \mathrm{~km}^{3}$ year. Currently, the regional passport includes 88 projects for the construction, modernization and reconstruction of treatment facilities - housing and communal services in more than 30 municipalities. However, due to the lack of a developed mechanism of state support for the implementation of investment projects, the rules for the provision of financial support from the federal budget and many other problematic issues, a delay in the implementation of measures to improve the Volga River is possible. In addition, it is proposed to liquidate (recultivate) the object of past environmental harm - the territory of the Burnakovskaya lowland of Nizhny Novgorod, which is a source of diffuse pollution of the Volga River, contaminated as a result of past economic activities for the storage, processing of oil products and oil sludge. From this territory, oil products are regularly transported to the Volga River. The solution of this issue was not included in the action plan of the priority project «Preservation and Prevention of Volga River Pollution». Also, the source of funding for the event on the elimination of the accumulated harm object in the territory of the Burnakovskaya lowland is currently not defined.
\end{abstract}

Keywords: Volga river, ecological state of water, Volga rehabilitation, treatment facilities, targets, financing of events

Высокий уровень антропогенного воздействия является основной причиной ухудшения экологического состояния реки Волги. В бассейн Волги регулярно поступают промышленные и коммунально-бытовые сточные воды, в которых содержатся нефтепродукты, сульфаты, хлориды, цинк, медь, фенолы и т.д. Сбрасываемые вещества ухудшают качество воды, опасны для экосистемы водоема, а также негативно влияют на водные биологические ресурсы и их местообитание. Помимо этого, река Волга является основным источником питьевого водоснабжения для Нижнего Новгорода и других городов Приволжского федерального округа, вследствие чего качество воды 
оказывает влияние на значительное количество населения [1-3].

Одним из направлений исполнения Указа Президента Российской Федерации от 7 мая 2018 г. № 204 «О национальных целях и стратегических задачах развития Российской Федерации на период до 2024 года» является национальный проект «Экология», в рамках которого разработан федеральный проект «Оздоровление Волги». Министерством экологии Нижегородской области в 2018 г. на основании предложений органов местного самоуправления был сформирован паспорт регионального проекта «Сохранение и предотвращение загрязнения реки Волги на территории Нижегородской области», который предусматривает реализацию мероприятий по проектированию и выполнению строительно-монтажных работ по строительству и реконструкции очистных сооружений. Главная цель запланированных мероприятий заключается в уменьшении сброса сточных вод в реку Волгу, что должно положительно сказаться на состоянии воды и повысить качество коммунальных услуг [4]. В связи с тем, что самоочищающая способность многих водотоков ниже приемлемого уровня, проведение природоохранных и оздоровительных мероприятий для водных объектов региона служит необходимым условием поддержания функционирования экосистем, а одним из актуальных вопросов современной гидроэкологии является изучение этих мероприятий с последующим анализом эффектов от их внедрения.

Цель работы заключалась в проведении анализа федерального проекта «Оздоровление Волги», внедряемого на территории Нижегородской области, и исследовании возможных экологических рисков при реализации мероприятий природоохранного проекта.

\section{Материалы и методы исследования}

В настоящее время среди множества причин снижения качества и устойчивости гидрологических объектов, в частности реки Волги, современные исследователи выделяют основные, происхождение которых так или иначе связано с антропогенным фактором:

- большая концентрация населения и размещение крупных промышленных предприятий по берегам реки, что является важнейшим аспектом экологического баланса Волги;

- содержание в сбрасываемых сточных водах множества химических соединений, обладающих токсичными свойствами и негативно влияющих на качество воды;
- недостаточная эффективность водоохранных и очистных мероприятий;

- наличие объектов накопленного экологического вреда (хронический фактор загрязнения);

- проблемы при регулировании водопользования и водоотведения;

- недостаточное внимание к вопросам диффузного и теплового загрязнения;

- проблема затонувших и брошенных водных транспортных средств (нефтеналивных, грузовых, пассажирских судов) [5].

Отдельно следует отметить влияние на экологическое состояние Волги плотин гидроэлектростанций, создание которых вызывает снижение качества речной воды и эффективности процессов самоочищения, способствует периодическому развитию синезеленых водорослей, а также ухудшению условий питьевого водоснабжения населения $[6,7]$.

Учитывая, что вся Нижегородская область находится в бассейне реки Волги, реализация мероприятий регионального проекта «Сохранение и предотвращение загрязнения реки Волги на территории Нижегородской области» планируется на территории практически всех муниципальных районов и городских округов Нижегородской области. В частности, планируется выполнение мероприятий по реконструкции и модернизации очистных сооружений на самых крупных предприятиях водоканализационного комплекса Нижегородской области, таких как «Нижегородский водоканал» и «Дзержинский водоканал», которые позволят осуществлять доочистку недостаточно очищенных сточных вод в размере 246 млн м $3 /$ год и 20 млн м $3 /$ год соответственно. Проектом предусмотрено достижение одного основного целевого показателя - снижение объема отводимых в реку Волга загрязненных сточных вод с 0,35 км$^{3}$ в 2019 г. до 0,12 км³ в 2024 г., что соответствует целевым показателям федерального проекта «О3доровление Волги» (табл. 1).

Финансирование мероприятий планируется за счет всех уровней бюджета. Общий планируемый объем финансирования на все 6 лет реализации проекта составляет 18791,27 млн руб., в том числе:

- $96 \%$ за счет средств федерального бюджета - 18 039,62 млн руб.;

- 4\% за счет средств консолидированного бюджета - 751,65 млн руб., из них:

- 80\% областной бюджет - 601,31 млн руб.; - 20\% местный бюджет - 150,34 млн руб. [8]. 
Основным методом исследований в работе явился сравнительный экспертный анализ проектных и экономических плановых данных, полученных из нормативной документации государственных структур управления природопользованием, с последующим исследованием степени реализации рассматриваемых проектов.

\section{Результаты исследования и их обсуждение}

Проведенный анализ перечней мероприятий по строительству, реконструкции (модернизации) очистных сооружений позволяет разделить их реализацию на несколько этапов.
I этап - 11 мероприятий строительномонтажных работ (далее - CMP), имеющих положительные заключения главной Государственной экспертизы со сроком реализации не старше 3 лет, заключения Министерства экономики и инвестиций Нижегородской области о максимальной (предельной) стоимости объекта, а также пакет документов, направленный на проверку в Минстрой РФ (табл. 2, рисунок). Анализ информации, предоставленной Департаментом Росприроднадзора по Приволжскому федеральному округу, показывает, что на этом этапе приоритетными были мероприятия, разработанные для объектов, оказывающих наибольшее негативное воздействие на реку Волгу.

Таблица 1

Значения показателей, планируемых к достижению для Нижегородской области [8]

\begin{tabular}{|l|c|c|c|c|c|c|}
\hline \multicolumn{1}{|c|}{ Наименование показателя } & \multicolumn{5}{|c|}{ Период, год } \\
\cline { 2 - 7 } & 2019 & 2020 & 2021 & 2022 & 2023 & 2024 \\
\hline $\begin{array}{l}\text { Снижение объема отводимых в реку Волгу загрязнен- } \\
\text { ных сточных вод, км }\end{array}$ в год & 0,35 & 0,33 & 0,29 & 0,26 & 0,18 & 0,12 \\
\hline $\begin{array}{l}\text { Прирост мощности очистных сооружений, обеспечива- } \\
\text { ющих сокращение отведения в реку Волгу, км³ в год }\end{array}$ & 0,00 & 0,02 & 0,06 & 0,09 & 0,17 & 0,23 \\
\hline
\end{tabular}

Таблица 2

Мероприятия, запланированные к реализации в рамках проекта «Сохранение и предотвращение загрязнения реки Волги на территории Нижегородской области» в 2019 г. [8]

\begin{tabular}{|c|c|c|}
\hline $\begin{array}{c}\text { № } \\
\Pi / \Pi\end{array}$ & $\begin{array}{l}\text { Муниципальный район } \\
\text { (городской округ) } \\
\text { Нижегородской области }\end{array}$ & Наименование мероприятия \\
\hline 1 & Арзамасский район & $\begin{array}{l}\text { Строительство наружных сетей канализации для мкр. Солнечный с. Хва- } \\
\text { товка Арзамасского района Нижегородской области }\end{array}$ \\
\hline 2 & Арзамасский район & $\begin{array}{l}\text { Строительство наружных канализационных сетей для отведения стоков } \\
\text { от многоквартирных жилых домов № } 1,2,3,20 \text { по ул. Полевой в с. Кирил- } \\
\text { ловка Арзамасского района Нижегородской области }\end{array}$ \\
\hline 3 & $\begin{array}{l}\text { Бутурлинский } \\
\text { район }\end{array}$ & $\begin{array}{l}\text { Реконструкция очистных сооружений производительностью } 1000 \text { м }{ }^{3} \text { ( } \\
\text { сутки в р.П. Бутурлино Бутурлинского района Нижегородской области } \\
\text { (ООО «Бутурлинский водоканал», р.П. Бутурлино, Бутурлинский рай- } \\
\text { он Нижегородской области) }\end{array}$ \\
\hline 4 & Воротынский район & $\begin{array}{l}\text { Строительство очистных сооружений канализации производительностью } \\
200 \text { м³/сутки в р.п. Васильсурск (МУП «Воротынское ЖКХ», р.п. Василь- } \\
\text { сурск, Воротынский район Нижегородской области }\end{array}$ \\
\hline 5 & Городецкий район & \begin{tabular}{|l} 
Биологические очистные сооружения хозяйственно-бытовых сточных \\
вод с. Смольки Городецкого района Нижегородской области
\end{tabular} \\
\hline 6 & г.о.г. Выкса & $\begin{array}{l}\text { Реконструкция БОС р.П. Досчатое (МУП «Стоки», р.П. Досчатое, город- } \\
\text { ской округ город Выкса Нижегородской области) }\end{array}$ \\
\hline 7 & г.о.г. Выкса & $\begin{array}{l}\text { Строительство КНС и напорного канализационного коллектора от БОС } \\
\text { р.П. Дружба до БОС р.П. Досчатое (МУП «Стоки», р.п. Досчатое, город- } \\
\text { ской округ город Выкса Нижегородской области) }\end{array}$ \\
\hline 8 & г.о.г. Саров & $\begin{array}{l}\text { Реконструкция здания механического обезвоживания осадков сточных } \\
\text { вод ОСК г. Сарова }\end{array}$ \\
\hline 9 & г.о. Семеновский & $\begin{array}{l}\text { Канализационные очистные сооружения и сети канализации в с. Ильино- } \\
\text { Заборское г. Семенов Нижегородской области }\end{array}$ \\
\hline 10 & Лысковский район & $\begin{array}{l}\text { Реконструкция канализационных очистных сооружений глубокой био- } \\
\text { логической очистки в г. Лысково Нижегородской обл. (МУП «Биологи- } \\
\text { ческие очистные сооружения», г. Лысково, Лысковский муниципальный } \\
\text { район Нижегородской области) }\end{array}$ \\
\hline 11 & Павловский район & $\begin{array}{l}\text { Строительство очистных сооружений канализации г. Ворсма Павловского } \\
\text { района Нижегородской области }\end{array}$ \\
\hline
\end{tabular}




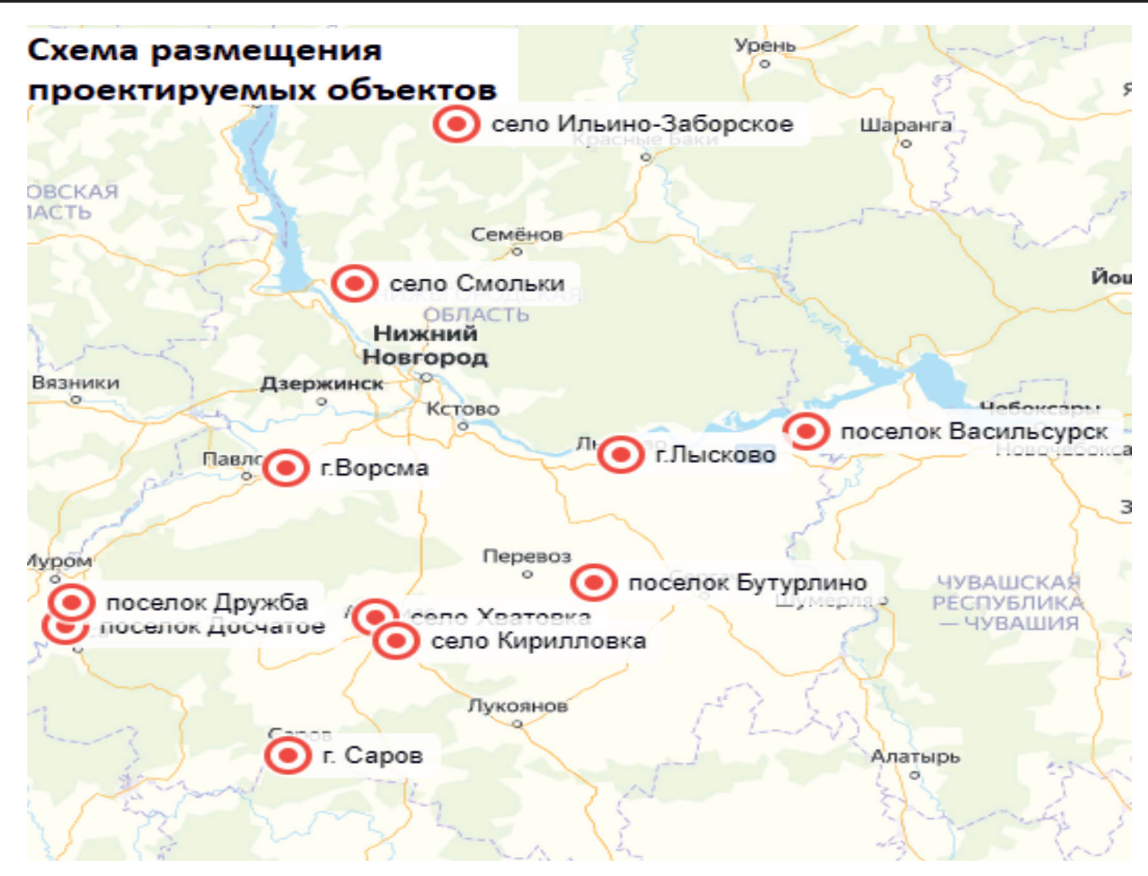

Территориальное размещение объектов I этапа реализации проекта «Сохранение и предотвращение загрязнения реки Волги на территорииНижегородской области»

Анализ выполнения запланированных работ показывает, что большинство мероприятий реализуются в соответствии с установленными сроками, за исключением плана реконструкции канализационных очистных сооружений глубокой биологической очистки в городе Лысково, для выполнения которого не найден подрядчик и не заключен контракт на выполнение работ [9].

План по реконструкции здания механического обезвоживания осадков сточных вод ОСК в городе Сарове также не реализован, так как аукцион на выполнение подрядных работ по объекту не состоялся [10].

II этап -8 мероприятий находятся на стадии проверки в главной Государственной экспертизе. После получения положительного заключения данной организации в оперативном режиме планируется внесение изменений в инвестиционную программу и далее - проведение СМР.

III этап - следующие 3 мероприятия находятся в стадии разработки проектной документации. По ее итогам возможна реализация мероприятий в рамках федеральной программы при условии исполнения алгоритма действий, предусмотренных этапами I и II.

IV этап - учитывая, что действующим механизмом финансирования проектов не предусмотрена возможность предоставления денежных средств на подготовку проектно-сметной документации, а также принимая во внимание высокую стоимость работ по разработке проектно-сметной документации на строительство, реконструкцию (модернизацию) очистных сооружений в рамках проекта «Оздоровление Волги» и ограниченность бюджетов муниципальных районов и городских округов Нижегородской области, Правительством Нижегородской области было принято решение о выделении дополнительной субсидии местным бюджетам за счет средств областного бюджета на разработку проектно-сметной документации.

План мероприятий для реализации в рамках проекта «Оздоровление Волги» был дополнен следующими мероприятиями, планируемыми к исполнению до 2021 г.:

- реконструкция цеха механического обезвоживания осадка, включая узел смешения осадка с опилками, БОС г. Заволжье Нижегородской области;

- реконструкция сооружений биологической очистки БОС г. Заволжье Нижегородской области;

- ликвидация сброса шламовых и промывных вод на станции обезжелезивания Тепловского водозабора г.о. г. Дзержинска Нижегородской области; 
- модернизация комплекса очистных сооружений на Нижегородской станции аэрации г. Нижнего Новгорода Нижегородской области;

- строительство сооружений для ликвидации сброса промывных вод, сбора и перекачки осадка в городскую канализацию на водопроводных станциях НовоСормовской, Слудинской и «Малиновая гряда» г. Нижнего Новгорода Нижегородской области;

- реконструкция и техническое перевооружение канализационных очистных сооружений г. Сарова Нижегородской области [11].

Главным показателем по проекту является снижение объема отводимых в реку Волгу загрязненных сточных вод. Снижение объемов сточных вод по проекту запланиро-

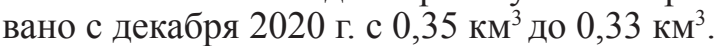
Также в рамках федерального проекта уже был достигнут первый контрольный результат: проведена оценка систем очистки сточных вод, сбрасываемых в реку Волгу крупнейшими водопользователями водопроводно-канализационного хозяйства, на соответствие нормативам [12].

Тем не менее на основании анализа указанной литературы необходимо отметить возможные риски и проблемные моменты, которые могут возникнуть при реализации проекта «Оздоровление Волги»:

- дефицит местных и региональных бюджетов на подготовку проектно-сметной документации;

- недостаточно высокое качество мероприятий, выполняемых в рамках контрактов, заключенных в соответствии с законодательством Российской Федерации в сфере закупок товаров, работ, услуг для обеспечения государственных и муниципальных нужд;

- динамичное изменение федерального законодательства;

- модернизация процесса производства работ, которая может привести к необходимости осуществления повторной экологической экспертизы даже при незначительных изменениях проектной документации, что способствует увеличению сроков реализации мероприятий;

- сложность финансирования и реализации ликвидации объектов накопленного вреда окружающей среде;

- низкая инвестиционная активность вследствие нестабильной экономической ситуации;

- необходимость внесения корректировок в действующее законодательство, кото- рые дадут возможность планировать наиболее экономически выгодные и эффективные проекты. В настоящее время действующее законодательство не позволяет строить линейные объекты (сети водоотведения), а при этом решение проблем многих населенных пунктов может обходиться дешевле в три раза при строительстве коллектора, чем при строительстве очистных сооружений;

- возможный риск повышения уровня платы граждан за коммунальные услуги в связи с тем, что появляются затраты не только на транспортировку сточных вод, но и на ее очистку, а также повышение затрат на эксплуатацию (зарплата персоналу, оплата электричества, реагентов и т.п.);

- стихийные бедствия и техногенные катастрофы.

В рамках федерального проекта «Оздоровление Волги» дополнительно предлагалось произвести ликвидацию (рекультивацию) объекта накопленного экологического вреда - территории Бурнаковской низины г. Нижнего Новгорода, являющегося источником диффузного загрязнения реки Волги. В 2018 г. был одобрен сводный план реализации проекта, а также поддержано предложение Правительства Нижегородской области об участии Нижегородской области в пилотном проекте по снижению поступления в реку Волгу загрязненного диффузного стока. В качестве пилотной территории, на которой будут отработаны концепция и технология снижения загрязнения от диффузного стока, выбрана территория Бурнаковской низины, где грунты вследствие деятельности в прошлом нефтеперерабатывающих предприятий загрязнены на десятки метров в глубину и служат источником загрязнения реки Волги [13].

К настоящему времени Минэкологии Нижегородской области совместно с ФГБУН «Институт водных проблем РАН» проведено обоснование стоимости работ по снижению загрязненного диффузного стока с территории Бурнаковской низины и направлено предложение по включению этого объекта в приоритетный проект «Оздоровление Волги» за счет средств федерального и областного бюджетов. Поскольку данное мероприятие не включено в региональный паспорт проекта, возникла проблема неопределенности источника финансирования из бюджетов, что приводит к увеличению сроков реализации мероприятия по ликвидации объекта накопленного вреда, а в случае отказа в финансировании - к его невыполнению. 


\section{Заключение}

Анализ реализации регионального проекта «Сохранение и предотвращение загрязнения реки Волги на территории Нижегородской области», разработанного в рамках федерального проекта «Оздоровление Волги», показал, что реализация мероприятий по строительству, модернизации и реконструкции очистных сооружений - объектов жилищно-коммунального хозяйства предусматривает четыре этапа. Реализация мероприятий, запланированных к выполнению на первом этапе, осуществляется в соответствии с установленными сроками, за исключением двух объектов.

Проект был дополнен рядом мероприятий, планируемых к выполнению в 2021 г. Помимо этого, разработано предложение по включению объекта накопленного экологического вреда на территории Бурнаковской низины, являющегося источником диффузного загрязнения реки Волги, в приоритетный проект «Оздоровление Волги».

Однако при реализации данного проекта существует множество рисков и проблемных моментов, в результате которых запланированный объем снижения

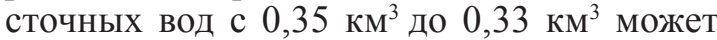
быть не достигнут. Таким образом, в настоящее время необходимы постоянное проведение анализа текущей обстановки по реализации региональных проектов оздоровления крупных водотоков, а также отслеживание экологической ситуации на указанной территории.

\section{Список литературы / References}

1. Исенаилева Ж.Н., Волкова И.В. Оценка качества среды аквальных комплексов дельты р. Волги // Международный журнал прикладных и фундаментальных исследований. 2012. № 1-1. C. 89-89.

Isenaileva Zh.N., Volkova I.V. Assessment of the quality of the environment of the water complexes of the Volga Delta // Mezhdunarodnyj zhurnal prikladnyh i fundamental'nyh issledovanij. 2012. № 1-1. P. 89-89 (in Russian).

2. Козлов А.В., Вершинина И.В. Анализ вариабельности общих, биохимических и экотоксикологических показателей в воде реки Волга и каналах дренажной системы города Балахны Нижегородской области // Успехи современного естествознания. 2019. № 11. С. 95-100.

Kozlov A.V., Vershinina I.V. Analysis of variability of general, biochemical and ecotoxicological indicators in the water of the Volga River and channels of the drainage system of the city of Balakhna of the Nizhny Novgorod region // Advances in current natural sciences. 2019. № 11. P. 95-100 (in Russian).

3. Лабунская Е.Н., Бухарицин П.И. Современное состояние фитопланктона и качество воды низовий Волги и Северного Каспия // Международный журнал прикладных и фундаментальных исследований. 2010. № 8. С. 136-138.

Labunskaya E.N., Buharicin P.I. Current state of phytoplankton and water quality of lower Volga and Northern Caspian
Sea // Mezhdunarodnyj zhurnal prikladnyh i fundamental'nyh issledovanij. 2010. № 8. P. 136-138 (in Russian).

4. Минэкологии региона направило заявку на включение Бурнаковской низины в государственный реестр объектов накопленного вреда. [Электронный ресурс]. URL: http:// mineco-nn.ru (дата обращения: 30.04.2020).

The Ministry of Ecology of the region sent an application for inclusion of the Burnakovsky lowland in the state register of objects of accumulated harm. [Electronic resource]. URL: http:// mineco-nn.ru (date of access: 30.04.2020) (in Russian).

5. Кручинин О.В. Глобальные экологические вызовы: оздоровление Волги // Труды научного конгресса 20-го Международного научно-промышленного форума «Великие реки 2018». Н.Новгород: ННГАСУ, 2018. Т. 1. С. 54-57.

Kruchinin O.V. Global environmental challenges: improving the Volga // Trudy nauchnogo kongressa 20-go Mezhdunarodnogo nauchno-promyshlennogo foruma «Velikie reki 2018». N.Novgorod: NNGASU, 2018. V. 1. P. 54-57 (in Russian).

6. Воронков В.В. Водохранилище на равнинной реке. Потери и угрозы (на основе прогноза последствий от подъема уровня Чебоксарского водохранилища) // Труды научного конгресса 14-го Международного научно-промышленного форума «Великие реки 2012». Н. Новгород: ННГАСУ, 2013. T. 1. C. 259-263.

Voronkov V.V. Reservoir on a flat river. Losses and threats (based on the forecast of the consequences of raising the level of the Cheboksary reservoir) // Trudy nauchnogo kongressa 14go Mezhdunarodnogo nauchno-promyshlennogo foruma «Velikie reki 2012». N. Novgorod: NNGASU, 2013. V. 1. P. 259263 (in Russian).

7. Краснов А.Н. Проблемы Чебоксарского водохранилища - Проект «Отметка 68» // Материалы Международной научно-практической конференции «Экологическое образование для устойчивого развития: теория и педагогическая реальность». Н.Новгород: ООО Типография «Поволжье», 2013. C. 373-381.

Krasnov A.N. Problems of the Cheboksary reservoir Project «Mark 68» // Materialy Mezhdunarodnoj nauchnoprakticheskoj konferencii «Ekologicheskoe obrazovanie dlya ustojchivogo razvitiya: teoriya i pedagogicheskaya real'nost'». N.Novgorod: OOO Tipografiya «Povolzh'ye», 2013. P. 373381 (in Russian).

8. Паспорт «Сохранение и предотвращение загрязнения реки Волги на территории Нижегородской области». 2018. 19 c.

Passport «Preservation and prevention of pollution of the Volga River in the territory of the Nizhny Novgorod region». 2018. 19 p. (in Russian).

9. Реконструкция канализационных очистных сооружений глубокой биологической очистки в г. Лысково [Электронный ресурс]. URL: https://synapsenet.ru/zakupki/fz44/ 0132300002019000049\%231--nizhegorodskaya-obl rekonstrukciya-kanalizacionnih (дата обращения: 21.05.2020).

Reconstruction of sewage treatment plants of deep biological treatment in the city of Lyskovo [Electronic resource]. URL: https:// synapsenet.ru/zakupki/fz44/0132300002019000049\%231--nizhegorodskaya-obl-rekonstrukciya-kanalizacionnih (date of access: 21.05.2020) (in Russian).

10. Выполнение подрядных работ по объекту «Реконструкция здания механического обезвоживания осадков сточных вод ОСК г. Сарова в части подготовки обезвоженного осадка к процессу компостирования» [Электронный pecypc]. URL: https://synapsenet.ru/zakupki/fz44/ $0132300007219000180 \% 231$-nizhegorodskaya-obl-vipolnenie-podryadnih-rabot-po (дата обращения: 21.05.2020).

Contracting for the project «Reconstruction of the building formechanical dewatering of sewage sludge from the OSK in Sarov regarding the preparation of dehydrated sludge for the composting process» [Electronic resource]. URL: https://synapsenet.ru/ zakupki/fz44/ 0132300007219000180\%231--nizhegorodskaya- 
obl-vipolnenie-podryadnih-rabot-po (date of access: 21.05.2020) (in Russian).

11. Отчет о ходе реализации регионального проекта Нижегородской области «Оздоровление Волги». Письмо Министерства экологии и природных ресурсов Нижегородской области. 2019. 3 с.

Report on the implementation of the regional project of the Nizhny Novgorod Region «Improvement of the Volga». Letter from the Ministry of Ecology and Natural Resources of the Nizhny Novgorod Region. 2019. 3 p. (in Russian).

12. Сведения о достижении результатов, контрольных точек и мероприятий. Отчет Министерства экологии и природных ресурсов Нижегородской области. 2019. 7 с.
Information on the achievement of results, milestones and events. Report of the Ministry of Ecology and Natural Resources of the Nizhny Novgorod Region. 2019. 7 p. (in Russian).

13. Исследования Росприроднадзора выявили крупные превышения допустимой концентрации нефтепродуктов в почве на территории «Бурнаковской низины» в Нижнем Новгороде. [Электронный ресурс]. URL: https://www.niann. $\mathrm{ru} /$ ?d=440150 (дата обращения: 30.04.2020) (in Russian).

Research by Rosprirodnadzor revealed large excesses of the permissible concentration of oil products in the soil on the territory of the Burnakovsky Lowland in Nizhny Novgorod. [Electronic resource]. URL: https://www.niann.ru/?id=440150 (date of access: 30.04.2020) (in Russian). 